\title{
SYSTEM FOR AUTOMATIC DISTRIBUTION AND WORKING WITH TECHNICAL DOCUMENTATION IN SMALL AND MICRO-SIZED INDUSTRIAL ENTERPRISES
}

\author{
Yuliyan Dimitrov
}
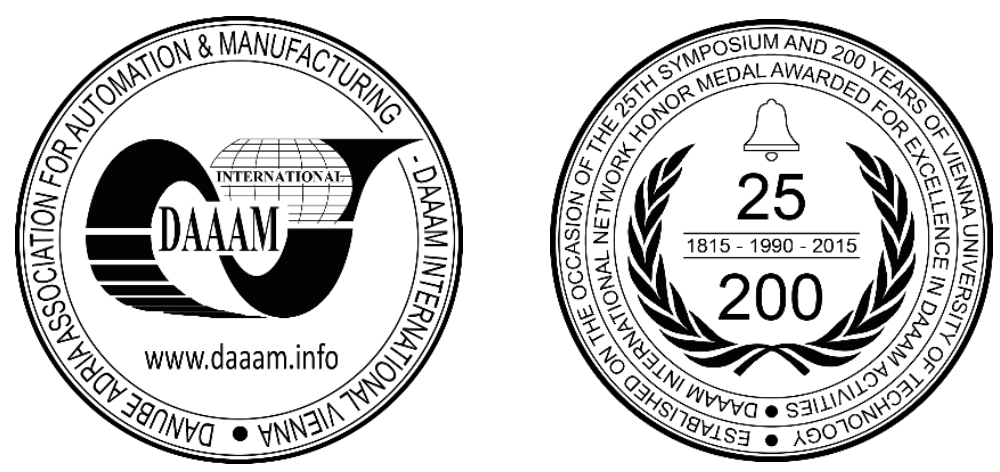

This Publication has to be referred as: Dimitrov, Y[uliyan] (2018). System for Automatic Distribution and Working with Technical Documentation in Small and Micro-Sized Industrial Enterprises, Proceedings of the 29th DAAAM International Symposium, pp.0976-0982, B. Katalinic (Ed.), Published by DAAAM International, ISBN 978-3-90273420-4, ISSN 1726-9679, Vienna, Austria

DOI: $10.2507 / 29$ th.daaam.proceedings.140

\begin{abstract}
The report presents authors' work on the process of distribution and handling of technical documentation in small and medium-sized industrial enterprises. A model of a draft project of the system is presented. The main structural units of the system and the interactions between them are developed. The advantages and features of the proposed system are outlined against similar existing ones. The main task was the use of CAD systems when working with technical documentation, minimize the use of technical documentation on paper; to train staff to work with advanced technologies for working with and exchanging documents; reduce the auxiliary working time and processing of technical documentation in the company. The developed system is registered in the Patent Office of the Republic of Bulgaria with a Utility model.
\end{abstract}

Keywords: drawing; CAD systems; engineers; training; technical documentation

\section{Introduction}

In recent years, the number of small and micro-sized enterprises (SMEs) in the EU has grown considerably and has become a major driver of employment. This growth in the EU for the period 2002-2008 is 13\% and for Bulgaria it is $24 \%$, ie. almost twice as high. The structure of SMEs over recent years has shown a rise in the share of micro-enterprises, above all at the expense of small businesses. Significantly higher for the period is also the growth of the number of jobs in SMEs - $41 \%$ for Bulgaria, compared to $12 \%$ for the EU-27; more than 3 times more jobs in the EU than in the EU. For the period 2005-2009, micro and small enterprises have made a major contribution to the growth of the SME sector.

The highest growth in the number of enterprises is shown by micro-enterprises $(33 \%)$ and in the case of small enterprises $(25 \%)$. The analysis of the state and the factors for the development of SMEs shows that they have relatively low innovation activity. This is evidenced by the statistics, with $80 \%$ of SMEs being innovative, and $11 \%$ relatively low. The most innovative are the enterprises in the sphere of production. Indicative of the low innovation activity of SMEs is the neglect of the implementation of digital and information technologies. 
The following factors can be analyzed as weakness for the development of SMEs in Bulgaria: (1) the relatively low investment and innovation activity, low activity in intellectual property and patents; (2) insufficient export items of output; (3) lack of interest in networking and related productions / clusters.

The first weakness determines the need to transfer knowledge, technology and innovation to SMEs, including in the form of services. Only $10 \%$ of SMEs can finance innovation, and only $3 \%$ have capacity and capabilities for their own research activity. Cooperation with research institutes and universities is limited - only $4 \%$ have used scientific research, and $10 \%$ have some cooperation with universities. Very low is still the share of SMEs that use information management systems - below $6 \%$.

These inadequate results indicate the need to transfer knowledge and experience in the form of engineering and technical services for computer design and construction, rapid prototyping and selection of manufacturing technology, From the above, the following conclusions can be drawn: small and medium enterprises are very important for the work of a developed modern economy, for the development of small and medium-sized engineering enterprises, it is very important to implement the modern information systems processes and technical documentation. [1], [2].

\section{Work with technical documentation and drawings in small and medium engineering enterprises.}

Proper and quick work with technical documentation and drawings is of great importance for the performance of an engineering firm. In modern companies with high level of organization of all processes in production are used powerful information systems. They are called ERP systems.

The acronym ERP stands for enterprise resource planning. It refers to the systems and software packages used by organizations to manage day-to-day business activities, such as accounting, procurement, project management and manufacturing. ERP systems tie together and define a plethora of business processes and enable the flow of data between them. By collecting an organization's shared transactional data from multiple sources, ERP systems eliminate data duplication and provide data integrity with a "single source of truth. Today, ERP systems are critical to manage small, medium and enterprise businesses across all industries. The organization of an ERP system and the interaction of the individual modules is shown in Figure 1. [15]

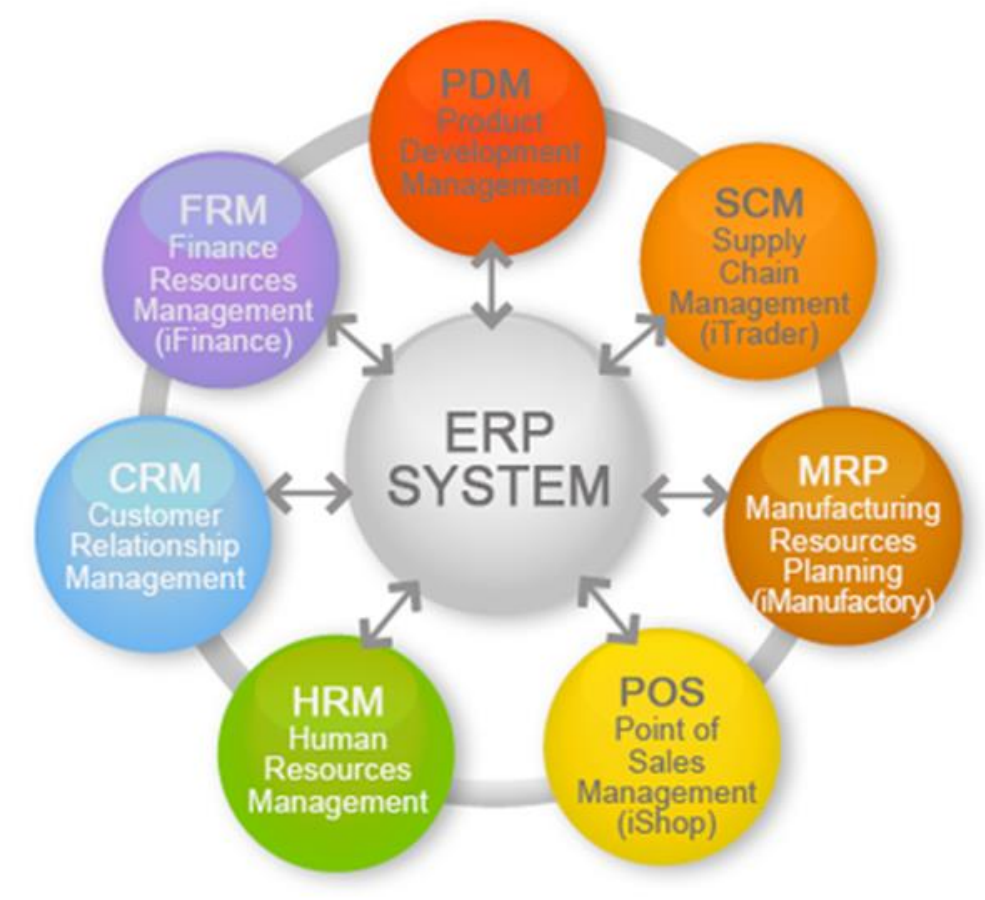

Fig. 1. Structure and interactions in ERP system [17].

The implementation and use of ERP systems in engineering companies has a number of advantages. But the implementation and maintenance of such a system is a very complex process requiring many human, hardware and software resources. Because of this, mainly large companies use ERP systems. For small and medium-sized engineering companies, these systems are a major financial cost for deployment and high financial costs for subsequent maintenance, which is why they very rarely use such systems [3], [4]. However, some companies decide to use only separate modules from the ERP systems. For engineering firms, due to the availability of many technical documentation and drawings, only the module for the organization of the technical documentation is most often used. This module is called Product Data Management (PDM). 
Product data management (PDM) is the use of software to manage product data and process-related information in a single, central system. This information includes computer-aided design (CAD) data, models, parts information, manufacturing instructions, requirements, notes and documents. The ideal PDM system is accessible by multiple applications and multiple teams across an organization, and supports business-specific needs. Choosing the right PDM software can provide a company in any industry with a solid foundation that can be easily expanded into a full product lifecycle management (PLM) platform - Figure 2.

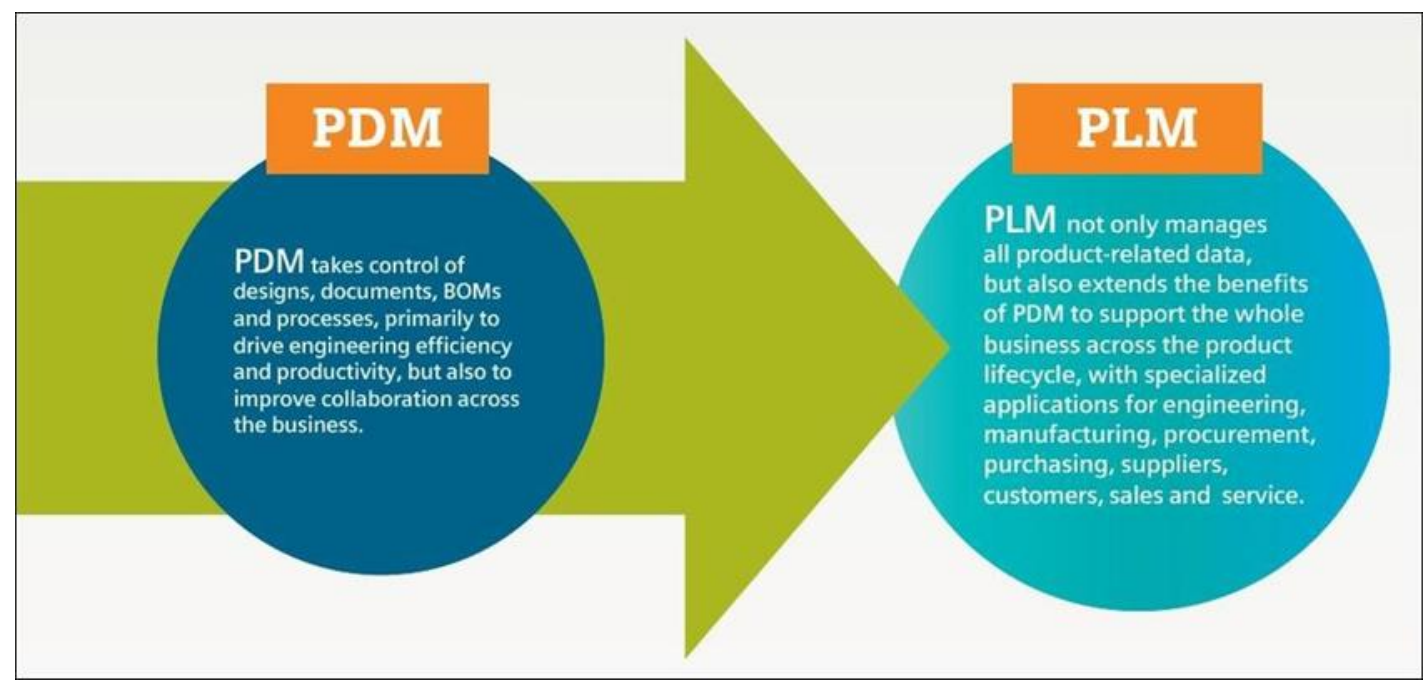

Fig. 2. Connections between PDM and PLM system [11].

At its core, a PDM system provides solutions for secure data management, process enablement, and configuration management. The average engineer loses $25 \%$ of their time to data management. That's time wasted searching for files, recreating data, updating systems and answering requests. PDM system makes data management easy with a single view to the latest multi-CAD and product data. Securely share more consumable data with non-engineering colleagues through role-based, self-service applications and 3D visualization technology.

Product data management (PDM) is the process of capturing and managing the electronic information related to a product so it can be reused in business processes such as design, production, distribution and marketing. It usually involves the use of a dedicated software application and centralized database. PDM typically encompasses multiple products' technical specifications, engineering models, design drawings, bills of materials (BOMs) and related documents. PDM software provides version control and security to ensure that the information stored in the central repository is accurate and up to date, which in turn can reduce data processing and make operations, such as manufacturing, more efficient. While engineers are typically the heaviest users, PDM is also employed by operations managers, salespeople, marketers and others who work with a product throughout its lifecycle.

PDM is a precursor and major component of product lifecycle management (PLM), a broader strategy for managing and collaborating around product information. PDM sprung from the computer-aided design (CAD) industry as a way to track CAD drawings and information. While PDM is a standard component of PLM, it is also offered as a dedicated module in many ERP suites [8], [10].

Product data management (PDM) is when a company uses a centralized software system to store all the information related to a product. This system feeds all the other systems within the company that require information about that product. This information can include everything from the raw materials used to construct that product to how it was built. The data can be used across a variety of business functions, from design to marketing [5],[6] .

PDM was originally used primarily for the computer aided design (CAD) process. Engineers needed a better way to keep up with paper documentations related to the development of a product. This centralized system was designed to keep up with all the data associated with a product. PDM continues to be used very heavily by engineers today, but also used by many others who build any product through a series of processes and raw material. Any business user who interacts with a product throughout its lifecycle benefits from the use of this information collected.

Information typically stored in PDM includes (Figure 3):

1. Technical specifications - measurements and materials

2. Drawings - electronic or manual visuals of the product.

3. Bill of materials - or BOMs, for raw materials.

4. Engineering documentations- how a product is constructed.

5. Other documents- example, photographed images of final product. 
A PDM system should be centralized and contain version control and security, which keeps the data accurate and adds accountability to those that manage the data. The PDM should be part of a larger, more encompassing, product lifecycle management system (PLM). A PLM includes the systems to which the PDM feeds data, such as an internet repository used for marketing the product online. A PLM is a more encompassing strategic series of systems used by the business to communicate about the product. A PLM encompasses every aspect of a product from inception to market deployment [7], [9].

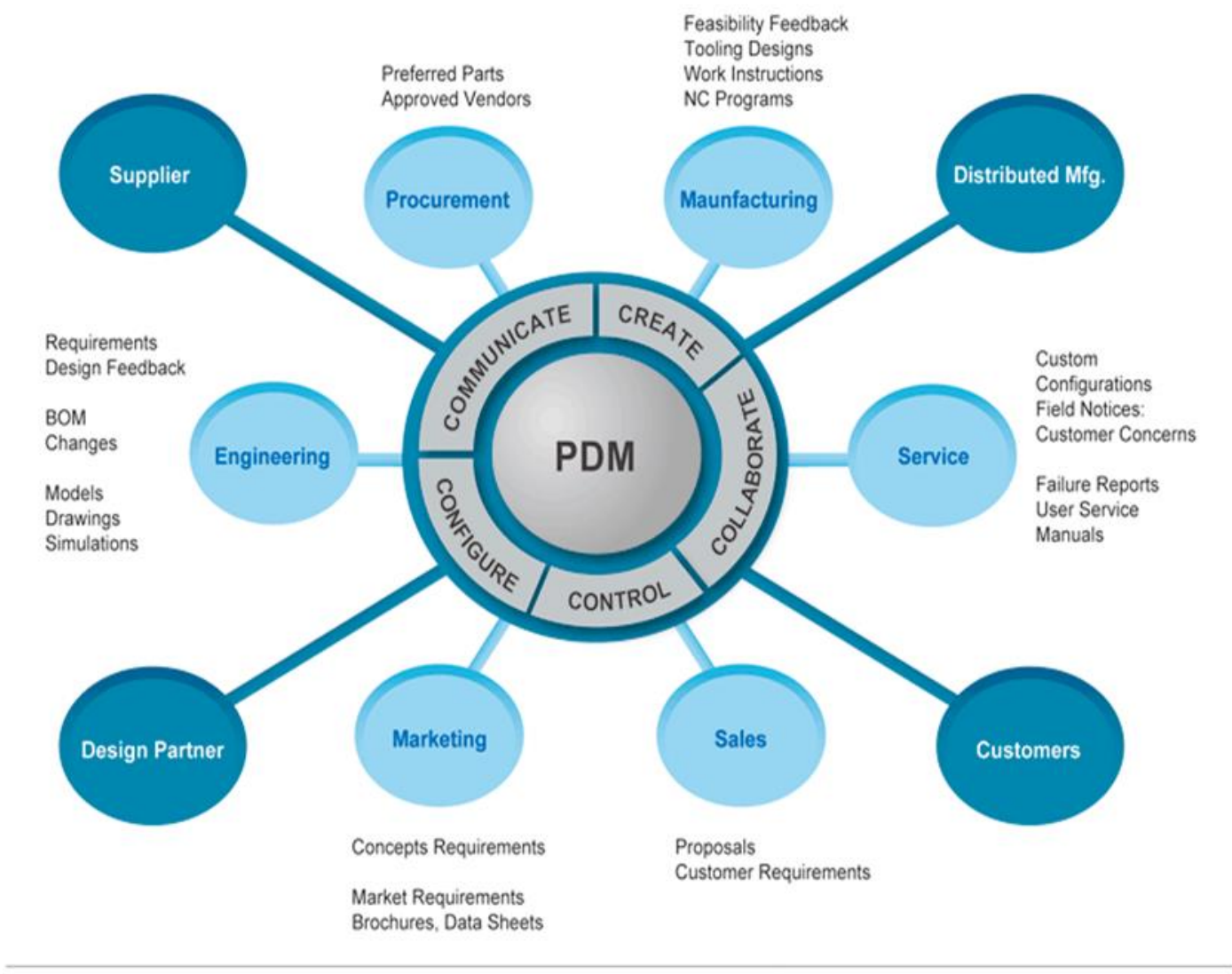

Fig. 3. Main processes in the PDM system. [16]

Although this system is only part of the large ERP system and requires fewer human and financial resources, very few Bulgarian small and medium-sized enterprises still use PDM systems in their organization when working with technical documentation. Therefore, a team of specialists from Rousse University and a private engineering firm in this field has developed a simplified version of the PDM system, with minimal resources supporting all the main processes in working with technical documentation.

\section{Presentation of the project}

The project is related to the process of distribution and handling of technical documentation in small and medium enterprises. The technical documentation is comprised of: structural documentation (drawings for the manufacture and installation of articles), diagrams, technical documents. It comes in two ways: creating a SolidWorks and AutoCAD CAD system from the computer file from the constructor of company and paper-based existing in company documentation or documentation of clients.

To be able to work with paper-based documentation through the system, it is converted into a computer file (image) by scanning. The technical documentation is submitted at the input of the system in digital form (computer files - images, format .jpeg or .pdf) from the company's constructor from his workstation. With specialized software (designed for this purpose), the documentation reaches the required working space in the production premises. The workstation is a machine equipped with a special tablet stand. The rack is mounted on a machine-friendly location, easy to handle with a tablet, good visibility.

The tablet is a "touch screen" with maximum screen size (10 inches-13 inches, diagonal) with reliable protection from strikes, chips, dust, oils, etc. At each workplace, the necessary technical documentation is provided to perform the technological process set out in the machine plan. The operator plays back the technical documentation of the current operation on the tablet screen. The tablet screen ensures maximum visibility of the technical documentation, incl. by increasing individual parts of the drawings, the ability to remotely change changes in the documentation, remarks. 
The system stores all documents in a database, allowing archiving and importing new documents at any time by the constructor. The constructor has the ability to remotely manage the documentation to the appropriate workstations. The system enables direct communication between a worker, engineer, and quality specialist.

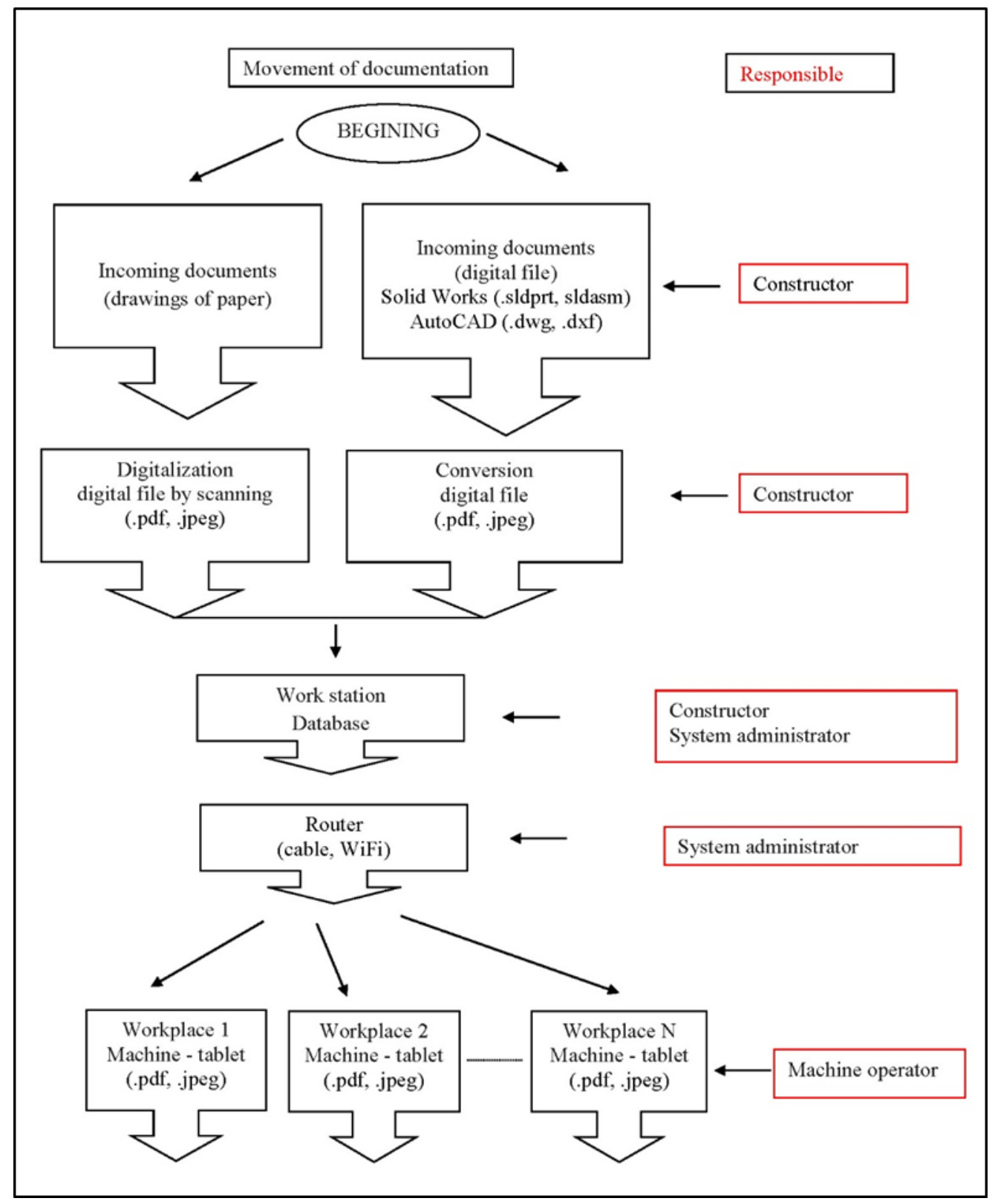

Fig. 4. Structure and operation scheme of "Automatic distribution system and working with technical documentation".

Project goals:

- Using CAD systems when working with technical documentation;

- Minimize the use of technical documentation on paper;

- Training the staff to work with advanced technologies for working with and exchanging documents;

- Reduce the auxiliary working time and processing of technical documentation in the company;

- Increase work efficiency and product quality by improving work with technical documentation and links between business units.

Project results:

- The developed system is registered in the Patent Office of the Republic of Bulgaria with a Utility model - Figure 5;

- Testing has been done to send documents to work machines via the Internet;

- The working process of a worker with a drawing machine was simulated using a tablet. 


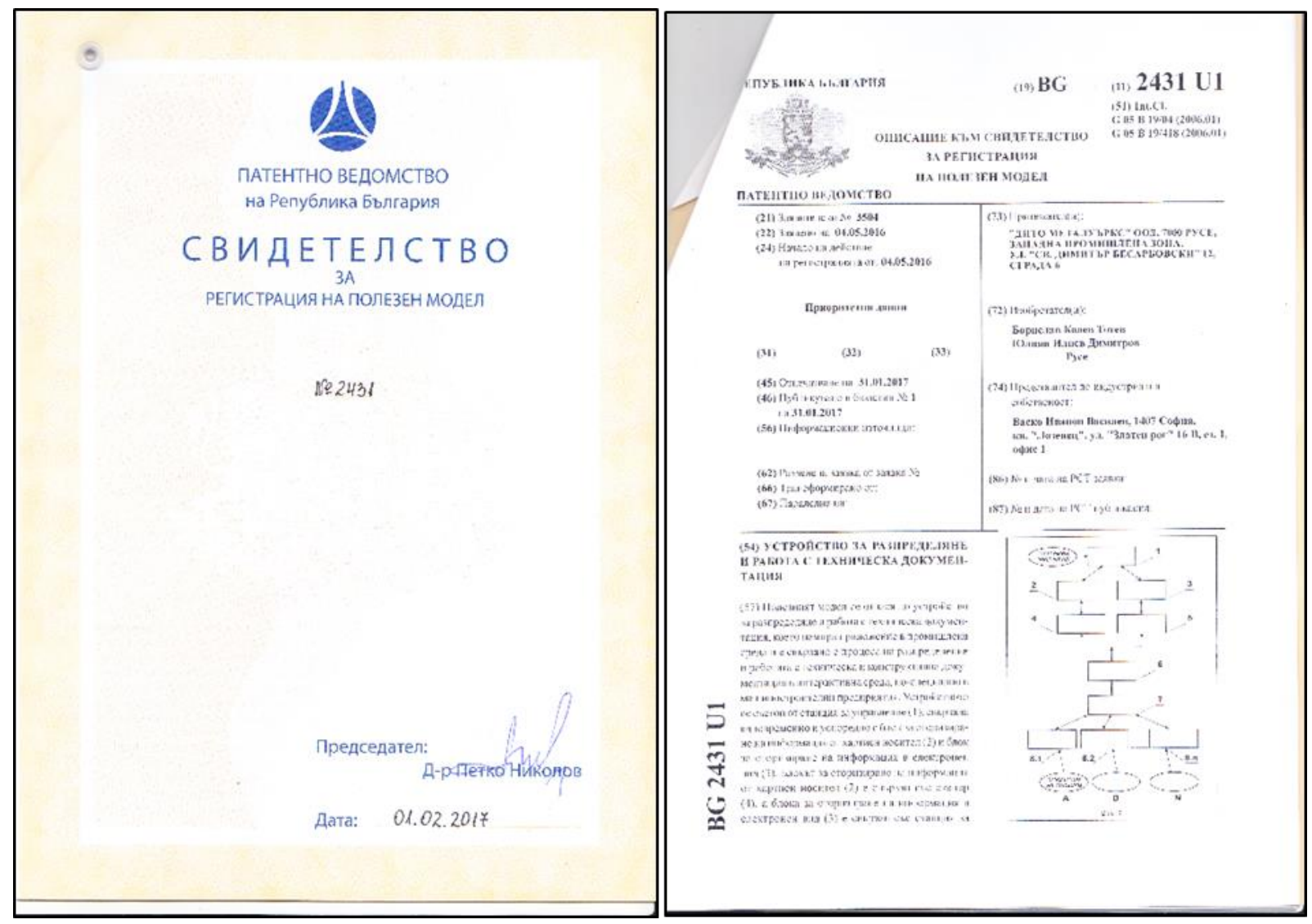

Fig. 5. Document of registration in the Patent Office of the Republic of Bulgaria with a Utility model.

\section{Conclusion}

A solution has been developed at an early stage for small and medium-sized enterprises to work with technical documentation under very light conditions. The projected system has a simple structure requiring small financial resources for dedicated hardware and minimal support. Also, many people with high and special qualifications are not required to work with technical documents. Work on the next stage continues with the development of the application software for operating the system.

\section{Acknowledgments}

This project would not be possible without the assistance of all colleagues from the department and the assistance of the private companies with which the Department of Machine science, Machine Elements and Engineering Graphics in University of Ruse.

\section{References}

[1] Найденов. Н. \& Недялков. Н. (2009). Управление на операциите, Русе, 2009, ISBN-13:978-954-337-069-6.

[2] Найденов. Н. \& Недялков. Н. (2012). Изследване на необходимостта от инженерно-технически услуги за малките и средните предприятия, Научна студия, Русе, 2012, ISBN 978-954-337-171-6

[3] Рьндин, А. \& Галкина, О. (2012).Автоматизация потоков документации - важньй шаг к созданию ЕИП СПб ОАО „Красньй Октябрь“, списание САПР и графика, Москва, бр.08.2012.

[4] Муленко. М., (2015). Компьютерные технологии и автоматизированные системы в машиностроении. РГУ нефти и газа им. И.М.Губкина, Москва.

[5] Mesihovic, S \& Malmqvist, J. (2000). Product Data Management (PDM) System Support for the Engineering Configuration Process, 14th European Conference on Artificial Intelligence ECAI 2000 Configuration Workshop, Berlin, Germany

[6] Pikosz, P. \& Malmqvist, J. (1997) Strategies for introducing PDM systems in engineering companies, Proceedings of CE, 1997 - books.google.com

[7] Riives, J.; Karjust, K.; Küttner, R.; Lemmik, R.; Koov, K.; Lavin, J., (2012). Software development platform for integrated manufacturing engineering system , 8th International DAAAM Baltic Conference "INDUSTRIAL ENGINEERING” 19-21 April 2012, Tallinn, Estonia 
[8] Gligora Marković, M.; Pogarčić, I. (2012). Šuman, S.,Managements' role in development of Information system, Annals of DAAAM for 2012. \& Proceedings of the 23rd International DAAAM Symposium, Vienna, 2012. 737742

[9] Suman. S.\&Pogarcic. I. (2016). Development of ERP and other large business systems in the context of new trends and technologies; Proceedings of the 27th DAAAM International Symposium, pp.0319-0327, Published by DAAAM International, ISBN 978-3-902734-08-2, ISSN 1726-9679, Vienna, Austria

[10] Tavcar, J. \& Duhovnik, J.(2000) Typical Models of Product Data Integration in Small and Medium Companies, International Journal Advanced Manufacturing Technology, Springer-Verlag London Limited, 16:748-758, ISSN: 1433-3015.

[11] https://community.plm.automation.siemens.com/t5/Teamcenter-Blog/Autodesk-PDM-for-AutoCAD-and-Inventorthat-can-grow-to-PLM/ba-p/393234

[12] https://searcherp.techtarget.com/definition/product-data-management-PDM

[13] http://cio.bg/2068_pdm_sistemite_osnovna_koncepciya_i_prilozhenie

[14] https://www.3ds.com/products-services/enovia/

[15] https://www.oracle.com/applications/erp/what-is-erp.html

[16] http://www.globalsys.com/products_pdm.aspx

[17] https://www.indiamart.com/proddetail/garment-manufacturing-erp-18295790273.html

[18] https://study.com/academy/lesson/what-is-product-data-management-definition-tools.html 